\title{
Gerakan Masyarakat Sehat Berbasis Masjid Sebagai Upaya Pengelolaan Mandiri Penyakit Kronik Degenaratif Di Desa Menganti Kecamatan Kesugihan Kabupaten Cilacap Tahun 2020
}

\author{
Arief Hendrawan ${ }^{1}$, Widyoningsih ${ }^{2}$ \\ ${ }^{1}$ Prodi D3 FisioterapiSTIKES Al-Irsyad Al-Islamiyyah, ${ }^{2}$ Prodi Profesi NersSTIKES Al-Irsyad Al-Islamiyyah \\ Email korespondensi: hendrarie@gmail.com
}

\begin{abstract}
Abstrak
Peningkatan gaya hidup menyebabkan peningkatan terhadap resiko penyakit degenerative. Biaya yang dikeluarkan untuk pengobatan penyakit degenerative cukup tinggi. Untuk menurunkan beban biaya tersebut diperlukan peran serta masyarakat terhadap gerakan masyarakat hidup sehat. Salah satu upaya untuk meningkatkan peran serta masyarakat adalah melalui optimalisasi peran masjid sebagai media dakwah keagamaan menjadi media dakwah sosial keagamaan. Pengabdian kepada masyarakat dilaksanakan sejak bulan Mei 2020 sampai dengan September 2020. Lokasi pengabdian berada di Masjid Nurul Huda Dusun Tembok Kecamatan Kesugihan Kabupaten Cilacap. Sasaran kegiatan adalah jamaah masjid berjumlah 18 orang. Metode pengabdian masyarakat adalah penyuluhan kesehatan tentang pengelolaan mandiri penyakit degenerative dan screening / pemeriksaan kesehatan penyakit degenerative jamaah masjid. Hasil yang didapat dari program pengabdian berupa peningkatan pemahaman jamaah tentang peran dan fungsi masjid sebagai sarana social keagamaan, peningkatan pemahaman jamaah tentang persiapan lansia menghadapi menjalani usia senja, pemahaman jamaah tentang penyakit degenerative dan peningkatan pemahaman tentang pengelolaan mandiri penyakit degenerative.
\end{abstract}

Keywords: masjid ; lansia ; penyakit degenerative

\begin{abstract}
Increased lifestyle causes an increased risk of degenerative diseases. The costs incurred for the treatment of degenerative diseases are quite high. In order to reduce the cost burden, community participation is required in the community movement for healthy living. One of the efforts to increase community participation is through optimizing the role of the mosque as a medium for religious da'wah to become a social religious media. Community service was carried out from May 2020 to September 2020. The location of the service was at Nurul Huda Mosque, Tembok Hamlet, Kesugihan District, Cilacap Regency. The target of the activity is 18 people in the mosque congregation. The community service method is health education and health screening / examination of mosque congregations abaout seltf treatment and screening degenerative desease. The results obtained from the service program were in the form of an increase in the congregation's understanding of the role and function of the mosque as a social religious facility, an increase in the congregation's understanding of the preparation for the elderly to face old age, the congregation's understanding of degenerative diseases and an increase in understanding of the independent management of degenerative diseases
\end{abstract}

Keywords: neuropathy, diabetic, training 


\section{PENDAHULUAN}

Pembangunan kesehatan Indonesia ditujukan untuk meningkatkan derajat kesehatan yang optimal pada masyarakat. Masalah kesehatan dapat dipengaruhi oleh pola hidup, pola makan, lingkungan kerja, olahraga dan stress.

Perubahan gaya hidup masyarakat menyebabkan peningkatan prevalensi terhadap penyakit degenerative (Allert, 2018). Penyakit degenerative merupakan jenis penyakit kronis. Penyebab secara umum dari penyakit degenerative adalah faktor penuaan (Risky, 2018). Menurut laporan dari WHO, hampir 17 juta orang meninggal lebih awal tiap tahunnya akibat dari penyakit degenerative. Berdasarkan hasil Riset Kesehatan Dasar (Riskesdas) tahun 2007 yang dilakukan di Indonesia juga menyimpulkan bahwa proporsi penyebab kematian tertinggi adalah penyakit degenerative yaitu penyakit kardiovaskular (31,9\%), hipertensi $(6,8 \%)$ dan stroke (15,4\%) (Kemenkes RI, 2013). Data dari Riskesdas Jateng (2018) menyebutkan bahwa untuk Kabupaten Cilacap, prevalensi penyakit degenerative hipertensi $(12,03 \%)$, penyakit sendi $(5,54 \%)$ dan diabetes mellitus $(1,28 \%)$.

Beban pembiayaan untuk ketiga jenis penyakit degenerative di atas cukup tinggi. Untuk mengurangi beban pembiayaan tersebut maka diperlukan peran serta aktif masyarakat guna menurunkan angka kejadian penyakit degenerative tersebut (Gugus, 2016). Diperlukan suatu upaya untuk memunculkan kesadaran masyarakat tentang hidup sehat.

Masjid memiliki fungsi utama sebagai tempat ibadah bagi umat muslim. Selain sebagai tempat ibadah, masjid juga berfungsi sebagai sarana sosial (Ali, 2020). Salah satu peran sosial masjid adalah penguatan peran strategis masjid dalam penerapan Germas dan Program Hidup Sehat (Gugus, 2016; Harismayanti, 2016; Siti, Sri, \& Nur, 2018).

Penyakit degenerative merupakan kondisi yang banyak dijumpai di masyarakat desa Menganti. Kondisi penyakit degenerative yang sering dijumpai adalah hipertensi, penyakit gangguan tulang sendidan diabetes mellitus. Banyak warga yang belum memahami kondisi penyakit kronis degenerative dan tindakan pengelolaan mandiri penyakit kronis degenerative tersebut. Di desa Menganti, masjid juga berperan sebagai tempat pertemuan warga di tingkat dusun. Salah satunya adalah Masjid Nurul Huda. Masjid Nurul Huda ini mengadakan pertemuan tiap minggu untuk kajian Islami. Pertemuan tersebut lebih ke arah pertemuan jamaah masjid wanita yang membahas tentang kajian Islam. Mayoritas jamaah 
yang ikut dalam pertemuan adalah ibu rumah tangga dan lansia. Sejauh ini, Masjid Nurul Huda belum pernah menyelenggarakan kegiatan selain kegiatan keagamaan. Dapat dikatakan bahwa masjid hanya berperan sebagai tempat untuk syiar agama belum sebagai sarana sosial. Jamaah kajian Islam yang mayoritas ibu rumah tangga dan lansia juga belum pernah mendapatkan informasi tentang kesehatan, khususnya informasi mengenai penyakit degenerative.

Berdasarkan kondisi di atas, penulis tertarik untuk melakukan pengabdian kepada masyarakat dengan judul "Gerakan Masyarakat Sehat Berbasis Masjid Sebagai Upaya Pengelolaan Mandiri Penyakit Kronik Degenaratif Di Desa Menganti Kecamatan Kesugihan Kabupaten Cilacap Tahun 2020".

\section{MASALAH}

Permasalahan yang dihadapi mitra dalam pengabdian masyarakat ini adalah :

1) Peningkatan pemahaman peserta tentang peran masjid sebagai sarana kegiatan social keagamaan

2) Peningkatan pemahaman peserta tentang penyakit degenerative

3) Peningkatan pemahaman peserta tentang pengelolaan mandiri penyakit degenerative

\section{METODE PELAKSANAAN}

Pengabdian kepada masyarakat dilaksanakan di Dusun Tembok Desa Menganti Kecamatan Kesugihan Kabupaten Cilacap pada bulan Mei s.d September 2020. Sasaran pada kegiatan pengabdian ini adalah jamaah masjid Nurul Huda berjumlah 18 orang jamaah. Metode pelaksanaan pengabdian kepada masyarakat ini adalah penyuluhan kesehatan. Gambaran umum pelaksanaan kegiatan pengabdian adalah sebagai berikut :

1) Tim pengabdian kepada masyarakat mengadakan survey lapangan dan koordinasi lapangan dengan ketua mitra pengabdian

2) Tim pengabdian kepada masyarakat menjelaskan rencana, tujuan dan tehnik pelaksanaan pengabdian kepada masyarakat

3) Tim pengabdian kepada masyarakat mengadakan kontrak pertemuan dengan mitra pengabdian 
4) Tim pengabdian kepada masyarakat melaksanakan kegiatan pengabdian yang meliputi kegiatan penyuluhan dan kegiatan pemeriksaan kesehatan.

\section{HASIL DAN PEMBAHASAN}

Hasil dan pembahasan kegiatan pengabdian adalah sebagai berikut :

\section{1) Hasil}

Kegiatan pengabdian diikuti oleh 18 peserta. Deskripsi peserta pengabdian seperti tampak pada tabel 1 dan tabel 2 .

Tabel 1 Distribusi Peserta Pengabdian Berdasarkan Jenis Kelamin

\begin{tabular}{lcc}
\hline & $\mathbf{n}$ & Jenis Kelamin \\
\hline 1 & 18 & Laki-laki $=0$ orang \\
& & Perempuan $=18$ orang \\
\hline
\end{tabular}

Tabel 2 Distribusi Peserta Pengabdian Berdasarkan Usia

\begin{tabular}{ccc}
\hline & n & Usia \\
\hline 1 & 18 & $<50$ tahun $=4$ orang \\
& & $51-55$ tahun $=2$ orang \\
& $>55$ tahun $=12$ orang \\
\hline
\end{tabular}

Tingkat pemahaman jamaah tentang peran masjid dalam bidang sosial dan keagamaan, kesiapan diri menghadapi / menjalani usia senja, penyakit degenerative dan pengelolaan mandiri penyakit degeneratif pada tabel 3

Tabel 3 Perbandingan Pemahaman Mitra Sebelum dan Sesudah Pengabdian Kepada Masyarakat

\begin{tabular}{|c|c|c|c|}
\hline \multirow[t]{2}{*}{ No } & \multirow[t]{2}{*}{ Item } & \multicolumn{2}{|c|}{ Hasil } \\
\hline & & Sebelum & Sesudah \\
\hline 1 & $\begin{array}{l}\text { Pemahaman peran masjid } \\
\text { bidang social keagamaan }\end{array}$ & $\begin{array}{l}\text { Tidak Paham : } 15 \text { orang } \\
(83,33 \%) \\
\text { Paham : } 3 \text { orang }(16,66 \%)\end{array}$ & $\begin{array}{l}\text { Tidak Paham : } 5 \text { orang }(27,7 \\
\%) \\
\text { Paham : } 10 \text { orang }(72,22 \%)\end{array}$ \\
\hline 2 & $\begin{array}{l}\text { Pemahaman Penyakit } \\
\text { Degeneratif }\end{array}$ & $\begin{array}{l}\text { Tidak Paham : } 10 \text { orang } \\
(72,22 \%) \\
\text { Paham : } 5 \text { orang }(27,22 \%)\end{array}$ & $\begin{array}{l}\text { Tidak Paham : } 3 \text { orang } \\
(16,66 \%) \\
\text { Paham : } 15 \text { orang }(83,33 \%)\end{array}$ \\
\hline 3 & $\begin{array}{l}\text { Pengelolaan Mandiri Penyakit } \\
\text { Degeneratif }\end{array}$ & $\begin{array}{l}\text { Tidak Paham : } 10 \text { orang } \\
(72,22 \%) \\
\text { Paham : } 5 \text { orang }(27,22 \%)\end{array}$ & $\begin{array}{l}\text { Tidak Paham : } 3 \text { orang } \\
(16,66 \%) \\
\text { Paham : } 15 \text { orang }(83,33 \%)\end{array}$ \\
\hline
\end{tabular}


Data identifikasi penyakit degenerative yang ditemukan tampak pada tabel 4

Tabel 4. Data Penyakit Degeneratif Jamaah

\begin{tabular}{llcll}
\hline No & \multicolumn{1}{c}{ Item } & n & Data $($ orang) & Keterangan \\
\hline 1 & Hipertensi & & 2 orang $(11,1 \%)$ & Normal \\
& & & 16 orang $(88,8 \%)$ & Hipertensi \\
2 & Asam Urat & & 5 orang $(27,7 \%)$ & Normal \\
& & & 10 orang $(72,2 \%)$ & Kadar Asam Urat Tinggi \\
3 & Gula Darah & 18 & 5 orang $(27,7 \%)$ & Normal \\
& & & 10 orang $(72,2 \%)$ & Kadar Glukosa Tinggi \\
4 & Nyeri Lutut & & 10 orang $(55,5 \%)$ & Penderita \\
5 & Nyeri Pinggang & 15 orang $(83,3 \%)$ & Penderita \\
6 & Neuropati Perifer & 10 orang $(72,2 \%)$ & Penderita \\
\hline
\end{tabular}
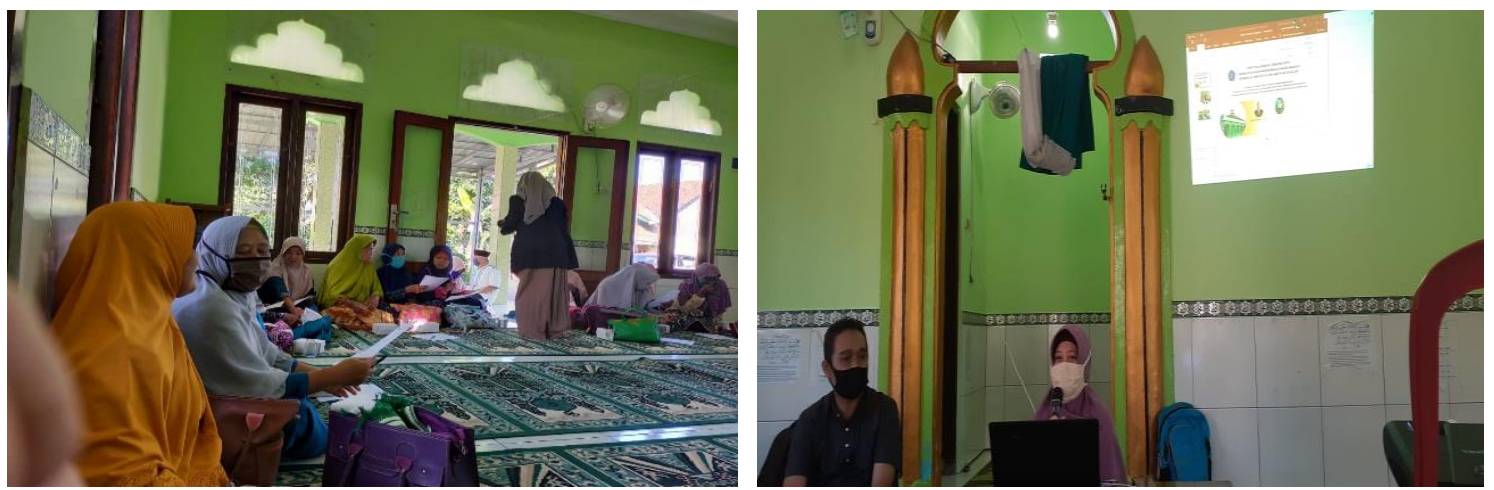

Gambar 1. Dokumentasi Kegiatan Pengabdian

\section{2) Pembahasan}

Pengabdian masyarakat dilaksanakan 4 kali kegiatan. Kegiatan pertama adalah kegiatan penyuluhan tentang peran serta masjid dalam kegiatan social keagamaan. Dalam kegiatan pertama ini juga diberikan materi penyuluhan tentang kesiapan mental lansia dalam menghadapi / menjalani usia senja. Kegiatan kedua adalah kegiatan penyuluhan tentang penyakit degenerative yang menyerang lansia. Kegiatan ketiga adalah screening / pemeriksaan kesehatan pada jamaah masjid. Kegiatan keempat adalah penyuluhan pengelolaan mandiri penyakit degenerative. Dalam kegiatan pengabdian ini, peserta kegiatan yang merupakan jamaah masjid sangat antusias dalam mengikuti kegiatan. Hal ini ditandai dengan pertanyaan-pertanyaan yang diajukan serta kehadiran peserta kegiatan yang mana semua peserta mengikuti kegiatan hingga selesai.

Beberapa hambatan ditemukan dalam pelaksanaan kegiatan pengabdian kepada masyarakat ini. Hambatan yang dijumpai antara lain : 
a. Kegiatan dilaksanakan dalam masa pandemic Covid-19 sehingga pelaksanaan kegiatan tatap muka / penyuluhan yang dilaksanakan secara langsung harus mematuhi protocol kesehatan. Hal ini menjadi hambatan karena hampir sebagaian besar peserta kegiatan belum mengerti dan memahami protocol kesehatan dalam masa adaptasi baru kehidupan normal.

b. Sebagian besar peserta pengabdian adalah ibu rumah tangga yang juga berprofesi sebagai petani. Hal ini berimbas pada penentuan jadwal pertemuan pengabdian yang harus diagendakan.

\section{KESIMPULAN}

Kesimpulan kegiatan pengabdian ini adalah:

1) Adanya peningkatan pemahaman peserta tentang peran masjid sebagai sarana kegiatan social keagamaan

2) Adanya peningkatan pemahaman peserta tentang penyakit degenerative

3) Adanya peningkatan pemahaman peserta tentang pengelolaan mandiri penyakit degeneratif

\section{DAFTAR PUSTAKA}

Ali, F. T. (2020). Lima Fungsi Sosial Masjid. Retrieved from https://minanews.net/limafungsi-sosial-masjid/

Allert, B. I. N. (2018). Kena Penyakit Degeneratif Lebih Awal akibat Gaya Hidup Buruk. Retrieved from https://www.alodokter.com/kena-penyakit-degeneratif-lebih-awalakibat-gaya-hidup-buruk

Gugus, S. (2016). DMI Gencarkan Germas Hidup Sehat Berbasis Masjid. Retrieved from https://sultrakini.com/berita/dmi-gencarkan-germas-hidup-sehat-berbasis-masjid

Harismayanti. (2016). PEMBERDAYAAN MASYARAKAT BERBASIS MASJID (STUDI KASUS LAYANAN SOSIAL DAN PENDIDIKAN MASJID BESAR AL-AMIN KECAMATAN MANGGALA MAKASSAR). Makasar.

Kemenkes RI. (2013). Gambaran Kesehatan Lanjut Usia Di Indonesia. Jakarta: Kemenkes RI. 
Risky, C. S. (2018). Memahami Penyakit Degeneratif Beserta Jenis-jenisnya. Retrieved from https://hellosehat.com/hidup-sehat/tips-sehat/penyakit-degeneratif/

Siti, D. C., Sri, W., \& Nur, L. M. (2018). PEMBERDAYAAN KELUARGA BERBASIS MASJID PADA MASYARAKAT SAMIN DUSUN JEPANG MARGOMULYO BOJONEGORO. Al Qalam, 24. 